\title{
SIMULTANEOUS DETERMINATION OF TYPE-A AND TYPE-B TRICHOTHECENES IN BARLEY SAMPLES BY GC-MS
}

\author{
María Ibáñez-Vea, Elena Lizarraga, Elena González-Peñas*
}

Organic and Pharmaceutical Chemistry Department

Faculty of Pharmacy, C.I.F.A., University of Navarra

Irunlarrea 1, 31008, Pamplona, Navarra, Spain

*Corresponding author: Elena González-Peñas PhD: Tel: +34 948 425653. Fax: +34

948 425652. E-mail: mgpenas@unav.es

E-mail addresses of all coauthors: María Ibáñez-Vea: mivea@alumni.unav.es; Elena

Lizarraga PhD: elizarraga@unav.es 



\section{ABSTRACT}

A validated method for the simultaneous determination of eight type-A and type-B trichothecenes in barley has been applied to the analysis of 44 samples from the 2007 harvest in Navarra (Spain). The procedure included simultaneous extraction of trichothecenes with acetonitrile and water (84:16), clean-up with Multisep ${ }^{\circledR}$ columns, derivatization of the extract and GC-MS analysis. During method validation, selectivity, linearity, precision and accuracy, limits of detection and quantification and recovery were evaluated. Recovery ranged from 92.0 to $101.9 \%$ (RSD $<15 \%$ ), except for nivalenol (NIV) (63.1\%), and the limits of detection and quantification ranged from 0.31 to $3.87 \mu \mathrm{g} \mathrm{kg}^{-1}$ and from 10 to $20 \mu \mathrm{g} \mathrm{kg}^{-1}$, respectively. The higher occurrence was found for deoxynivalenol (DON) (89\% of the samples), although at concentrations below the maximum permitted level. The calculated dietary intakes of DON, NIV and the sum of T-2 and HT-2 were below the TDI values proposed. Two or more trichothecenes were present in $41 \%$ of the samples and so, the mycotoxin cooccurrence, and therefore synergic or additive effects, should be taking into account when determining permitted levels or risk assessment.

Keywords: Trichothecenes, mycotoxins, validation, GC-MS, barley.

Abbreviations: 3-acetyldeoxynivalenol (3-ADON). 15-acetyldeoxynivalenol (15ADON). $\alpha$-Chloralose (CLO). Diacetoxyscirpenol (DAS). Deoxynivalenol (DON). Fusarenon-X (FUS-X). Gas chromatography with mass spectrometry detection (GCMS). Internal standard (IS). Limit of detection (LOD). Limit of quantification (LOQ). Neosolaniol (NEO). Nivalenol (NIV). Pentafluoropropionic anhydride (PFPA). Selected-ion monitoring (SIM). Tolerable daily intake (TDI). Ultraviolet detection (UV). 


\section{Introduction}

Mycotoxins are toxic secondary metabolites produced by several fungal species growing on many agricultural commodities and processed food (Bennett and Klich, 2003). Trichothecenes constitute a mycotoxin family mainly produced by fungi of the Fusarium genus that grow in the field and contaminate different foodstuffs. They appear as natural contaminants in cereal grains such as wheat, barley, oat, maize, rice, and derived products, such as bread, malt and beer (Pronk, Schothorst and van Egmond, 2002).

There are more than 170 known trichothecenes (Krska, Baumgartner and Josephs, 2001), which can be classified into four categories (A, B, C and D) according to their chemical structure. Type-A trichothecenes are characterized by the presence of a hydrogen, a hydroxyl or an ester group at $\mathrm{C}-8$ position (R5 substituent in fig. 1), whereas type-B trichothecenes have a carbonyl group in this position. The most important trichothecenes, due to their toxicity and their world-wide prevalence are T-2 and HT-2 toxins, diacetoxyscirpenol (DAS) and neosolaniol (NEO) (type-A trichothecenes); and deoxynivalenol (DON), nivalenol (NIV), 3-acetyldeoxynivalenol (3-ADON), 15-acetyldeoxynivalenol (15-ADON) and fusarenon-X (FUS-X) (type-B trichothecenes) (Pronk, Schothorst and van Egmond, 2002). The chemical structure of trichothecenes analysed in this study are shown in figure 1.

[Insert figure 1 about here]

Several surveys have shown toxicological and immunological effects on farm animals, produced by trichothecenes after ingestion of mold-contaminated cereal grains. The 
main symptoms observed, especially for DON, are skin and gastrointestinal irritation or necrosis, haematological disorders, diarrhea, vomiting and feed refusal, decreased body weight gain, damage to the haematopoietic systems in bone narrow, spleen, thymus and lymph nodes and immunological alterations (Pronk, Schothorst and van Egmond, 2002). These compounds are potent inhibitors of protein and DNA and RNA synthesis (Rotter, Prelusky and Pestka, 1996). With regard to human diseases, these compounds have been related to several poison outbreaks such as alimentary toxic aleukia (ATA) and Akakaby-bio or red mould disease (Miller, 2008).

Trichothecenes levels in different matrices vary from $\mu \mathrm{g} \mathrm{kg}^{-1}$ up to $\mathrm{mg} \mathrm{kg}^{-1}$ depending on toxin, matrix, climatic conditions, as well as other factors. Since toxins can never be completely removed from the food supply and they are potential health risks for humans and animals, the European Union has implemented regulations for some of them. In the case of DON in cereals and derived products the maximum permitted level in unprocessed cereals has been established at $1250 \mu \mathrm{g} \mathrm{kg}^{-1}$ (European Commission, 2006a). With regard to T-2 and HT-2, the European Commission has stated that the presence of these toxins can be of concern for public health. Therefore, the development of reliable and sensitive methods, collection of more occurrence data and more investigations/research in the factors involved in the presence of T-2 and HT-2 toxin in cereals and cereal products, are necessary and of high priority (European Commission, 2006a). Regulations with respect to these toxins are still being considered. Discussion limit for the sum of T-2 and HT-2 was $100 \mu \mathrm{g} \mathrm{kg}^{-1}$ for unprocessed cereals and cereals products (Meneely, Ricci, van Egmond and Elliott, 2010).

The co-occurrence of different trichothecenes (type-A and type-B) in one same foodstuff, could originate at least additive effects on human or animal health; however, 
the knowledge regarding this aspect is still scarce. In order to be able to monitor several toxins, it is necessary to develop analytical methods for their simultaneous analysis that meets the regulatory requirements. This question is a great challenge for chemical analysts due to the heterogeneity of food matrices and the physicochemical characteristics of the toxins (Köppen, Koch, Siegel, Merkel, Maul and Nehls, 2010).

Several analytical methods for the determination and quantification of trichothecenes in food and feed commodities have been described in the reference literature, which have subsequently been reviewed by some researchers (Krska, Baumgartner and Josephs, 2001; Meneely, Ricci, van Egmond and Elliott, 2010; Langseth and Rundberget, 1998; Krska and Molinelli, 2007; Lattanzio, Pascale and Visconti, 2009). However, most of these studies are based on the extraction and clean-up of a single mycotoxin (usually DON) or a group of related mycotoxins (type-A or type-B), instead of the simultaneous analysis of type-A and type-B trichothecenes. In Spain, methods have recently been reported for the determination of DON and NIV in corn-based food products (Castillo, Montes, Navarro, Segarra, Cuesta and Hernández, 2008), for the simultaneous analysis of five type-A and -B trichothecenes (T-2, HT-2, DAS, DON and NIV) in wheat flour (Sospedra, Blesa, Soriano and Manes, 2010), and for the determination of DON, T-2 and HT-2 in cereal-based food (Cano-Sancho et al., 2010).

Some surveys regarding the presence of trichothecenes in cereals have been carried out on cereals from Europe (Biselli and Hummert, 2005), Finland (Eskola, Parikka and Rizzo, 2001), Lithuania (Keblys, Flaoyen and Langseth, 2000) and Norway (Langseth and Elen, 1997; Langseth and Rundberget, 1999), but to the knowledge of the authors, this is the first time that the co-occurrence of eight type-A and type-B trichothecenes has been studied in barley samples from Spain. 
In this paper, a sensitive and validated method was developed and successfully applied to the simultaneous analysis of eight type-A and type-B trichothecenes in 44 barley samples collected in Navarra (Spain) during 2007 harvest. The procedure involves one simple extraction process with acetonitrile and water for all of the analytes, and the clean up of the extract with Multisep ${ }^{\circledR}$ columns. The samples were then derivatized to be analyzed by GC-MS.

\section{Experimental}

\subsection{Chemical and reagents}

Trichothecenes standards were purchased from Fluka (Schnelldorf, Germany) as certified reference materials and pentafluoropropionic anhydride (grade derivatization 99\%) from Aldrich (Schnelldorf, Germany). Acetonitrile HPLC grade, $\alpha$-chloralose, imidazole, sodium bicarbonate and sodium sulphate anhydrous were supplied by SigmaAldrich (St. Quentin Fallavier, France) and pro-analysis grade toluene by Panreac (Barcelona, Spain). Millipore type I water was obtained daily from a Milli-Q waterpurifying system. Multisep ${ }^{\circledR} 227$ Trich+ columns were purchased from Romer Labs ${ }^{\circledR}$ (Tulln, Austria).

\subsection{Barley samples}

Different agricultural cooperatives and factories dedicated to the production of foodstuffs and feed provided barley samples of $1 \mathrm{~kg}$ after applying their own sampling procedures. Samples were collected from the barley 2007 harvest in Navarra, a region of northen Spain. All of the samples were stored at $4^{\circ} \mathrm{C}$ until their analysis. 


\subsection{Standard solutions}

A stock standard solution containing $8 \mathrm{mg} \mathrm{L}^{-1}$ of DON, 3-ADON, 15-ADON, NIV, FUS-X, T-2, HT-2, NEO and DAS were prepared by diluting trichothecene commercial solution volumes in acetonitrile. Working standard solutions containing 0.8 or $0.2 \mathrm{mg} \mathrm{L}^{-1}$ of each one of the analytes were prepared by diluting appropriate volumes of the stock standard solution with acetonitrile. An internal standard solution of $300 \mu \mathrm{g} \mathrm{L}^{-1}$ was prepared by diluting $\alpha$-chloralose in acetonitrile. All of the solutions were stored at $-20^{\circ} \mathrm{C}$ and maintained at room temperature for 30 minutes before each use.

For calibration sample preparation, blank barley sample extracts were fortified with an appropriate amount of a multi-analyte working standard solution, and then the extract was derivatized in a similar way as the samples.

\subsection{Extraction and clean up from barley samples}

The method used for trichothecene extraction from barley samples is based on that described by Milanez, Valente-Soares and Baptista (2006) and Langseth, Bernhoft, Rundberget, Kosiak and Gareis (1999). Three hundred grammes of barley were ground in a Restch ZM100 mill, using a sieve size of $0.75 \mathrm{~mm}$. Ten grammes of milled sample were extracted with $40 \mathrm{~mL}$ of a mixture of acetonitrile-water $(84: 16, \mathrm{v} / \mathrm{v})$ in an orbital shaker SSL1 $\left(\right.$ Stuart $\left.^{\circledR}\right)$ for $60 \mathrm{~min}$. The extract was filtered by gravity and then $10 \mathrm{~mL}$ of the filtrate were passed through a Multisep ${ }^{\circledR} 227$ Trich+ column from Romer Labs ${ }^{\circledR}$. Two hundred microliters of the $\alpha$-chloralose internal standard solution was added to $6 \mathrm{~mL}$ of the purified extract in order to correct errors during the derivatization procedure; the mixture was then evaporated to dryness in an evaporator (GeneVac) 
under vacuum at $60^{\circ} \mathrm{C}$. Finally, the residue was redissolved in $200 \mu \mathrm{L}$ of acetonitrile and transferred to an eppendorf for subsequent derivatization.

\subsection{Derivatization}

The derivatization process was similar to the method proposed by Langseth et al. (1999). Trichothecenes were derivatized by adding $100 \mu \mathrm{L}$ of pentafluoropropionic anhydride (PFPA) and $500 \mu \mathrm{L}$ of $0.4 \mathrm{M}$ imidazole in toluene-acetonitrile $(85: 15, \mathrm{v} / \mathrm{v})$. The mixture was shaken and heated at $60^{\circ} \mathrm{C}$ for $60 \mathrm{~min}$ in a ThermoShaker TS1 (Biometra, Germany). Then the solution was cooled and washed twice with $1 \mathrm{~mL}$ of $\mathrm{NaHCO}_{3} 5 \%\left(4^{\circ} \mathrm{C}\right)$ and once with $1 \mathrm{~mL}$ of water in order to remove derivatization reagent excess. A portion of sodium sulphate was added to the toluene phase in order to remove the water and then, the extract was transferred to an auto-sampler and analyzed in less than $2 \mathrm{~h}$. This period of time was determinated after carrying out a stability study using calibration samples.

\subsection{Equipment and chromatographic conditions}

Chromatographic analyses were performed in an Agilent Technologies $6890 \mathrm{~N}$ gas chromatography system with a G2613A autosampler injector and coupled to a 5973 quadrupole mass spectrometer controled by ChemStation software (Agilent Technologies). Separation was achieved on an HP-5MS capillary column (30 m x $0.25 \mathrm{~mm}$ i.d.) coated with a $0.25 \mu \mathrm{m}$ film of stationary phase (5\% phenyl-methylsiloxane) from Agilent Technologies. High purity helium was used as carrier gas at a constant flow of $1.1 \mathrm{~mL} \mathrm{~min}^{-1}$. Injection volume was of $2.0 \mu \mathrm{L}$ in splitless mode. The injector was held at $250^{\circ} \mathrm{C}$ and the transfer line to detector at $300^{\circ} \mathrm{C}$. The GC oven temperature was programmed as follows: $120^{\circ} \mathrm{C}$ for $2 \mathrm{~min}, 30^{\circ} \mathrm{C} \mathrm{min}^{-1}$ to 
$175^{\circ} \mathrm{C}$, then $10^{\circ} \mathrm{C} \min ^{-1}$ to $220^{\circ} \mathrm{C}$ and finally $25^{\circ} \mathrm{C} \mathrm{min}^{-1}$ to $275^{\circ} \mathrm{C}$ holding $6 \mathrm{~min}$. The source temperature was $230^{\circ} \mathrm{C}$. The mass spectrometer was operated in electron impact mode (EI, $70 \mathrm{eV})$. A solvent delay of 4 min was used in order to avoid overloading the mass spectrometer with the solvent. The selected-ion monitoring (SIM) conditions were studied for DON, 3-ADON, 15- ADON, NIV, FUS-X, T-2, HT-2, NEO and DAS.

\subsection{Validation of the analytical method}

Validation of the analytical method was based on the following criteria: selectivity, linearity, limit of detection and limit of quantification, precision (within- and betweenday variability), accuracy and recovery. Calibration samples were prepared as matrixmatched standards to compensate the matrix effects.

Selectivity of the method was studied checking the retention time of each derivatized mycotoxin in the sample to see if it corresponded with the retention time in the matrixmatched calibration standard with a tolerance of $\pm 0.5 \%$ and also observing the mass spectrum of each peak in SCAN conditions. Moreover, the mass spectrum from each compound peak confirmed its presence in the sample, and the quantification in SIM conditions assured the selectivity of the method.

In the assessment of linearity, two calibration curves were plotted for each mycotoxin in the ranges $10-200 \mu \mathrm{g} \mathrm{kg}^{-1}$ and $200-2000 \mu \mathrm{g} \mathrm{kg}^{-1}$, except for DON and HT-2 for which $20-200 \mu \mathrm{g} \mathrm{kg}^{-1}$ and $200-2000 \mu \mathrm{g} \mathrm{kg}^{-1}$ ranges were evaluated. The concentration ranges were chosen to cover the respective limits of detection of each toxin as well as the maximum permitted level for DON in unprocessed cereals. Three replicates of six matrix-matched calibration standards were analyzed for each range. Calibration curves were evaluated by the analysis of the distribution properties of the residuals: when 
plotting the toxin concentration versus the residual points, a random distribution without reflecting any tendency must be achieved, correlation coefficient $r>0.990$, and the slope of the linear calibration curve statistically different from $0(p=95 \%)$.

Accuracy, repeatability and intermediate precision of the instrument were assayed by analyzing trichothecene calibration samples at low, medium and high levels of each calibration curve: 10 (20 for DON and HT-2), 80, 200, 800 and $2000 \mu \mathrm{g} \mathrm{kg}^{-1}$, per triplicate on one day and on three different days, respectively. The accuracy has been calculated as the standard error of the mean of the data obtained during the precision study, and the repeatability and intermediate precision as the relative standard deviation (RSD) in \%.

The limit of detection (LOD) was established analyzing three spiked barley samples at five different concentrations $\left(2.5,5,7.5,10,12 \mu \mathrm{g} \mathrm{kg}^{-1}\right)$ for each mycotoxin. LOD was calculated using a method based on the calibration curve extrapolation at zero concentration. This method consists in plotting the toxin concentration versus the peak area (curve 1) and versus the standard deviation obtained for each toxin level (curve 2). In order to calculate the LOD values, the following equation was used:

$$
L O D=\frac{y+\left(k \cdot y^{\prime}\right)}{b \cdot \sqrt{n}}
$$

with $y$ and $b$ being the values for $y$-intercept and slope, respectively, from curve $1 ; \mathrm{y}$ ' being the $y$-intercept from curve 2 and $n$ being the number of replicates for each level $(\mathrm{n}=3)$. The $\mathrm{k}$ value was 3 for LOD (Asociación Española de farmaceúticos de la Industria (A.E.F.I), 2001).

The limit of quantification (LOQ) corresponds to the minimum concentration with adequate precision ( $\mathrm{RSD} \leq 20 \%$ for $\mathrm{DON}$ and $\leq 40 \%$ for $\mathrm{T}-2$ and $\mathrm{HT}-2$ ) and recovery 
(between 60 and 110\% for DON; between 60 and 130\% for T-2 and HT-2) values (European Commission, 2006b).

Within- and between-day precision and recovery of the method were tested at 20, 100 and $1000 \mu \mathrm{g} \mathrm{kg}^{-1}$ levels for each trichothecene in spiked milled barley samples. The samples were spiked with adequate volumes of trichothecene standard solutions, and processed after 24 hours in order to ensure evaporation of the solvent. Recovery was determined extrapolating the absolute responses (area of toxin peak/area of IS peak) obtained from the barley spiked samples in the calibration curve; the calculated concentration was compared with the expected concentration for a $100 \%$ recovery. The repeatability and intermediate precision of this process were tested carrying out the complete sample process and recovery experiment on one day and on three different days, respectively. Where relevant, measured trichothecene levels were corrected for any natural contamination, as indicated by the analysis of the non-spiked samples. All the results were corrected by recovery.

\subsection{Quality control of the method}

During sample analysis, the method has been evaluated according to the results obtained in calibration samples that were simultaneously analyzed. One calibration sample of 25 , $75,200,400$ or $2000 \mu \mathrm{g} \mathrm{kg}^{-1}$ of each toxin were intercalated every group of 8 samples. No more than $75 \%$ of them should overcome the $15 \%$ value for accuracy.

\section{Results}

\subsection{Analysis conditions}


Sufficient yields were obtained from the derivatization reactions and type-B trichothecenes gave the highest yields of all. Only the derivatization reaction of NEO (a type-A trichothecene) gave a yield so low that it was impossible to obtain adequate limits of detection and quantification; therefore, this mycotoxin could not be evaluated in barley samples.

The SIM conditions have been established after studying the mass spectra of the derivatized compounds obtained in SCAN mode. In the case of type-B trichothecenes, the characteristic fragmentations of the derivatized molecules are based mainly on successive losses of fluorated groups such as $-\mathrm{OCOCF}_{2} \mathrm{CF}_{3},-\mathrm{CH}_{2} \mathrm{OCOCF}_{2} \mathrm{CF}_{3},-\mathrm{CF}_{3}$, and the carbonyl, methyl or methoxy groups. Type-A trichothecenes are more susceptible to the elimination of the acetyl, epoxy, isovaleryl, $-\mathrm{CH}_{2} \mathrm{COOCH}_{3}$ and methyl groups from the molecule. On the other hand, the molecular ion was observed in only the mass spectra of the derivatives of DON, FUS-X and HT-2 (m/z $=734,792$ and 716 , respectively).

Mycotoxins 15-ADON and 3-ADON eluted at the same retention time; however, the quantification has been possible due to the difference on their peak spectra. In the case of $15-\mathrm{ADON}$, the loss of $-\mathrm{OCOCF}_{2} \mathrm{CF}_{3}$ and $-\mathrm{CH}_{2} \mathrm{OCOCH}_{3}$ groups, originates an ion of $\mathrm{m} / \mathrm{z}=394$, whereas for $3-\mathrm{ADON}-\mathrm{PFP}_{2}$ derivative, the fragmentation of the methoxy group is favored, producing an ion of $\mathrm{m} / \mathrm{z}=588$. Table 1 summarizes the retention times and the selected ion monitoring for each analyte.

[Insert table 1 about here]

\subsection{Chromatographic conditions}


This method has permitted the simultaneous quantification of eight trichothecenes in a short time (17 min) (see figure 2). A good resolution for all mycotoxins was achieved, except for 3-ADON and 15-ADON.

[Insert figure 2 about here]

\subsection{Method validation}

Each compound was quantified by monitoring the ions shown in table 1, except for 3ADON and 15-ADON. For these compounds, quantification was made with a single ion $(\mathrm{m} / \mathrm{z}=588$ for $3-\mathrm{ADON}$ and $\mathrm{m} / \mathrm{z}=394$ for $15-\mathrm{ADON})$.

The linearity study showed an adequate relationship between the instrumental response $(y=$ area of toxin peak/area of IS peak $)$ and the respective trichothecene concentration (x). In addition, the linearity criteria have been achieved in the two ranges studied for all of the toxins (see table 1). Instrumental precision and accuracy showed adequate values $(<15 \%)$ in the ranges evaluated for all of the mycotoxins.

The LOD and LOQ values for the toxins in barley samples are shown in table 2. Recovery percentages at the three tested levels were between 92.0 and $101.9 \%$, except for NIV, the most polar molecule, which showed a lower recovery (63.1\%). In addition, recoveries were homogeneous at the levels assayed which demonstrated the precision of the method (see table 2).

[Insert table 2 about here]

\section{4. Trichothecenes in barley samples}


This method has been successfully applied to the analysis of 44 barley samples picked up during the 2007 harvest in Navarra (Spain). In table 3, trichothecene levels found in barley samples are shown.

[Insert table 3 about here]

The median value was calculated taking into account the levels between the LOD and LOQ; for the samples with a value lower than the LOD, the LOD/2 value was used. In the study of the presence of mycotoxins in samples, the samples considered were those which had mycotoxin levels above the LOD.

Only $7 \%$ of the samples had nondetectable levels for the mycotoxins; therefore, most of the samples presented one or more trichothecenes. Fifty-two percent of the samples contained levels of one single trichothecene. The greater occurrence in samples was for DON because $89 \%$ of the samples presented this type-B trichothecene, although none of them exceeded the maximum permitted level by legislation $\left(1250 \mu \mathrm{g} \mathrm{kg}^{-1}\right)$, with $119.9 \mu \mathrm{g} \mathrm{kg}^{-1}$ being the maximum level found. NIV had a lesser occurrence because only 3 samples presented this toxin, while FUS-X was detected in only one sample. Type-A trichothecenes were present with lesser incidence than DON. DAS was present in $4.5 \%$ of the samples, while T-2 and HT-2 were present in $11 \%$ and $23 \%$, respectively.

Co-occurence of mycotoxins has been observed in the samples (see figure 3). Forty-one percent of the samples presented two or more different toxins. Two, three and four mycotoxins co-occurred in the 14,18 and $9 \%$ of the samples, respectively. Twenty percent of the samples contained 15-ADON and/or 3-ADON, and all of them also presented DON levels. In $18 \%$ of the samples, there was a combination of DON + HT-2 
and in the $7 \%$ of the samples, there was DON + HT-2 + T-2. T-2 always appeared together with HT-2 and both mycotoxins co-ocurred in $11 \%$ of the samples.

[Insert figure 3 about here]

\section{Discusion}

This validated method has fulfilled all criteria pre-established for selectivity, linearity, precision (within- and between-day) and accuracy and limits of detection and quantification. The recovery values fulfill the requirements established in the Commission Regulation (EC) N $\mathrm{N}^{\mathrm{0}} 401 / 2006$ (recovery between 60 and 110\% in the $100-$ $500 \mu \mathrm{g} \mathrm{kg}^{-1}$ levels, and between 70 and $120 \%$ in the $>500 \mu \mathrm{g} \mathrm{kg}^{-1}$ levels for DON; between 60 and 130\% for T-2 and HT-2) (European Commission, 2006b).

The LOQ for DON is below the maximum permitted limit in cereals set by legislation (European Commission, 2006a), and to the author's knowledge, the LODs obtained for the trichothecenes in barley are lower or similar to others described for cereals in the reference literature (Eskola, Parikka and Rizzo, 2001, Schothorst and Jekel, 2001, Lattanzio, Solfrizzo and Visconti, 2008).

In view of the adverse effects caused by mycotoxins, and the continuous need for exposure data for risk assessment, the validated method has been successfully applied to the analysis of 44 barley samples from Navarra (Spain). Trichothecene levels present in barley from Spain are lesser than in other European countries, although with higher incidence (Langseth and Elen, 1997, Müller, Reimann, Schumacher and Schwadorf, 1997). According to a SCOOP report (2003), the trichothecene contamination rates in barley samples from 12 European countries were 47, 8, 4, 3 and 5\% for DON, NIV, 3-ADON, T-2 and HT-2, respectively, with 37 and $15 \mu \mathrm{g} \mathrm{kg}^{-1}$ being the DON and NIV 
mean concentration values, respectively (SCOOP, 2003). In this study, 89, 9, 14, 11 and $23 \%$ of the samples presented these toxins, respectively, with a median level of 11 and $1 \mu \mathrm{g} \mathrm{kg}^{-1}$ for DON and NIV. The higher occurrence of trichothecenes observed could be due to the low limits of detection of the applied method. In surveys of barley from Norway, Germany and Uruguay, several samples were contaminated with DON concentrations exceeding $1000 \mu \mathrm{g} \mathrm{kg}^{-1}$ (Langseth and Elen, 1997, Müller, Reimann, Schumacher and Schwadorf, 1997, Pan, Bonsignore, Rivas, Perera and Bettucci, 2007); however, in our study, the highest value was $119.9 \mu \mathrm{g} \mathrm{kg}^{-1}$.

With regard to T-2 and HT-2 values, studies from northern Europe showed higher mean concentrations in barley samples. In Norway, $22 \%$ and $5 \%$ of barley samples were positive for HT-2 and T-2, with a mean concentration in positive samples of 73 and $85 \mu \mathrm{g} \mathrm{kg}^{-1}$ (Langseth and Rundberget, 1999). The incidence of these toxins during five years in an area of southwest Germany varied between 0 and $9 \%$ and 2 and $29 \%$, respectively, with mean contents at $8-288$ and $2-305 \mu \mathrm{g} \mathrm{kg}^{-1}$, respectively (Müller, Reimann, Schumacher and Schwadorf, 1997). A high incidence for HT-2 and T-2 (34\% and $14 \%$ ) was found in barley samples from Lithuania, with a mean concentration in the positive samples of 41 and $40 \mu \mathrm{g} \mathrm{kg}^{-1}$, respectively (Keblys, Flaoyen and Langseth, 2000). Nevertheless, the maximum level found in this survey did not exceed 16.4 and $22.6 \mu \mathrm{g} \mathrm{kg}^{-1}$ for HT-2 and T-2, respectively.

In Spain, the determination of five trichothecenes (DON, NIV, DAS, T-2, HT-2) in twenty samples of white wheat flour resulted in the nondetection of the mycotoxins in the samples studied (Sospedra, Blesa, Soriano and Manes, 2010); the incidence of DON and NIV in corn-based food products was lower than in similar foods analyzed in other EU countries (Castillo, Montes, Navarro, Segarra, Cuesta and Hernández, 2008); and 
the determination of DON, T-2 and HT-2 in cereals-based food showed a high occurrence of DON, but the majority of the samples presented levels under the limit established by the EU, and a low incidence for T-2 and HT-2 (Cano-Sancho et al., 2010).

The European Scientific Committee on Food (SCF) evaluated Fusarium toxins such as DON, NIV, T-2 and HT-2, and established a tolerable daily intake (TDI) of $1 \mu \mathrm{g} \mathrm{kg}^{-1}$ b.w. per day for DON (Scientific Committee on Food (SCF), 2002), which is in line with the temporary tolerable daily intake established by the Nordic Working Group (Eriksen and Alexander, 1998), and the provisional maximum tolerable daily intake (PMTDI) established by the Joint Expert Committee on Food Additives (JECFA) (World Health Organization (WHO), 2001). The SCF also set a temporary TDI (t-TDI) of 0.7 and $0.06 \mu \mathrm{g} \mathrm{kg}^{-1}$ b.w. per day for NIV and for the sum of T-2 and HT-2, respectively (Scientific Committee on Food (SCF), 2002). No data regarding ingestion of barley or barley-derived products in Spain was found, but the mean consumption of cereals in this country is approximately $239 \mathrm{~g}$ day $^{-1}$ (Varela, Moreiras, Carbajal and Campo, 1995). Using this value, along with the mycotoxins levels obtained in this study, the calculated dietary intake of the trichothecenes expected for an adult of $70 \mathrm{~kg}$ is below the values proposed for TDI, except for the sum of T-2 and HT-2 taking into account the maximun value obtained (see table 4).

[Insert table 4 about here]

Nevertheless, these calculations led to an overestimation of daily intake because they were based on data regarding cereal intake instead of barley intake; therefore, the risk of 
human exposure to trichothecenes from barley-derivative consumption does not appear to be of great concern.

\section{Conclusions}

In this paper, a procedure has been successfully validated for the simultaneous quantification of DON, 3-ADON, 15- ADON, NIV, FUS-X, T-2, HT-2 and DAS in barley using the same analysis procedure for all of them along with a GC-MS technique.

After using this method for analysing 44 real samples, the calculated dietary intakes of mycotoxins were below the proposed TDI values. The co-occurrence of several mycotoxins in the same sample confirms the importance of having reliable analytical methods for simultaneous monitoring of trichothecenes in barley and in other foodstuffs. This also shows that co-occurrence of mycotoxins should be taken into account as well as synergic or additive effects when determining permitted levels or carrying out risk assessment.

\section{Acknowledgements}

The authors are grateful to the personnel of the participating local grain delivery sites for their cooperation. We wish to extend our gratitude to Ms. Laura Stokes for reviewing the English version of this manuscript. We thank the Project of Research of University of Navarra (PIUNA Projects) and CAN Fundation (Caja Navarra; "Proyectos: Tú eliges, tú decides") for the financial support received. 


\section{References}

Asociación Española de farmaceúticos de la Industria (A.E.F.I) (2001). Asociación Española de Farmacéuticos de la Industria. Validación de métodos analíticos. Barcelona: AEFI.

Bennett, J. W., M. Klich (2003). Mycotoxins. Clin. Microbiol. Rev., 16(3), 497-516.

Biselli, S., C. Hummert (2005). Development of a multicomponent method for Fusarium toxins using LC-MS/MS and its application during a survey for the content of T-2 toxin and deoxynivalenol in various feed and food samples. Food Addit.Contam., 22(8), $752-760$.

Cano-Sancho, G., F. M. Valle-Algarra, M. Jiménez, P. Burdaspal, T. M. Legarda, A. J. Ramos, et al. (2010). Presence of trichothecenes and co-occurrence in cereal-based food from Catalonia (Spain). Food Control, 22 (3-4), 490-495.

Castillo, M. A., R. Montes, A. Navarro, R. Segarra, G. Cuesta, E. Hernández (2008). Occurrence of deoxynivalenol and nivalenol in Spanish corn-based food products. Journal of Food Composition and Analysis, 21, 423-427.

Eriksen, G. S., Alexander, J. (1998). Fusarium toxins in cereals- a risk assessment. Nordic Council of Ministers. TemaNord (pp. 7-58). Copenhagen, Denmark:.

Eskola, M., P. Parikka, A. Rizzo (2001). Trichothecenes, ochratoxin A and zearalenone contamination and Fusarium infection in Finnish cereal samples in 1998. Food Addit. Contam., 18(8), 707-718.

European Commission (2006a). Commission regulation (EC) No 1881/2006 of 19 December 2006 setting maximum levels for certain contaminants in foodstuffs. Official Journal of the European Union, L 364, 5-24.

European Commission (2006b). Commission regulation (EC) No 401/2006 of 23 February 2006 laying down the methods of sampling and analysis for the official 
control of the levels of mycotoxins in foodstuffs. Official Journal of the European Union, L 70, 12-34.

Keblys, M., A. Flaoyen, W. Langseth (2000). The occurrence of type A and B trichothecenes in Lithuanian cereals. Acta Agric. Scand., Sect. B, Soil and Plant Sci., 50, 155-160.

Köppen, R., M. Koch, D. Siegel, S. Merkel, R. Maul, I. Nehls (2010). Determination of mycotoxins in foods: current state of analytical methods and limitations. Appl. Microbiol Biotechnol, 86, 1595-1612.

Krska, R., S. Baumgartner, R. Josephs (2001). The state-of-the-art in the analysis of type-A and -B trichothecene mycotoxins in cereals. Fresenius J. Anal Chem, 371, 285299.

Krska, R., A. Molinelli (2007). Mycotoxin analysis: state-of-the-art and future trends. Anal. Bioanal. Chem., 387(1), 145-148.

Langseth, W., A. Bernhoft, T. Rundberget, B. Kosiak, M. Gareis (1999). Mycotoxin production and cytotoxicity of Fusarium strains isolated from Norwegian cereals. Mycopathologia, 144(2), 103.

Langseth, W., O. Elen (1997). The occurrence of deoxynivalenol in Norwegian cereals Differences between years and districts, 1988-1996. Acta agriculturce Scandinavica. Section B, Soil and plant science, 47(3), 176.

Langseth, W., T. Rundberget (1999). The occurrence of HT-2 toxin and other trichothecenes in Norwegian cereals. Mycopathologia, 147, 157-165.

Langseth, W., T. Rundberget (1998). Instrumental methods for determination of nonmacrocyclic trichothecenes in cereals, foodstuffs and cultures. J. Chromatogr. A, 815, 103-121. 
Lattanzio, V. M. T., M. Pascale, A. Visconti (2009). Current analytical methods for trichothecene mycotoxins in cereals. Trends in Analytical Chemistry, 28(6), 758-768.

Lattanzio, V. M. T., M. Solfrizzo, A. Visconti (2008). Determination of trichothecenes in cereals and cereal-based products by liquid chromatography-tandem mass spectrometry. Food Addit. Contam., 25(3), 320-330.

Meneely, J. P., F. Ricci, H. P. van Egmond, C. T. Elliott (2010). Current methods of analysis for the determination of trichothecene mycotoxins in food. Trends in Analytical Chemistry, doi:10.1016/j.trac.2010.06.012.

Milanez, T., L. Valente-Soares, G. Baptista (2006). Occurrence of trichothecene mycotoxins in Brazilian corn-based food products. Food control, 17(4), 293.

Miller, J. D. (2008). Mycotoxins in small grains and maize: Old problems, new challenges. Food Addit. Contam., 25(2), 219-230.

Müller, H. M., J. Reimann, U. Schumacher, K. Schwadorf (1997). Natural occurrence of Fusarium toxins in barley harvested during five years in an area of southwest Germany. Mycopathologia, 137, 185-192.

Pan, D., F. Bonsignore, F. Rivas, G. Perera, L. Bettucci (2007). Deoxynivalenol in barley samples from Uruguay. Int. J. Food Microbiol., 114, 149-152.

Pronk, M. E. J., R. C. Schothorst, H. P. van Egmond (2002). Toxicology and occurrence of nivalenol, fusarenon $\mathrm{X}$, diacetoxyscirpenol, neosolaniol and 3- and 15acetyldeoxynivalenol: a review of six trichothecenes. RIVM, (Report 388802024/2002).

Rotter, B. A., D. B. Prelusky, J. J. Pestka (1996). Toxicology of deoxynivalenol (vomitoxin). J. Toxicol. Env. Health, 48, 1-34.

Schothorst, R. C., A. A. Jekel (2001). Determination of trichothecenes in wheat by capillary gas chromatography with flame ionisation detection. Food Chem., 73, 111117. 
Scientific Committee on Food (SCF) (2002). Opinion of the Scientific Committee on Food on Fusarium toxins. Part 6: Group evaluation of T-2 toxin, HT-2 toxin, nivalenol and deoxynivalenol. 12.

SCOOP (2003). SCOOP Task 3.2.10: Collection of occurrence data of Fusarium toxins in food and assessment of dietary intake by the population of EU Member States.

Sospedra, I., J. Blesa, J. M. Soriano, J. Manes (2010). Use of the modified quick easy cheap effective rugged and safe sample preparation approach for the simultaneous analysis of type A- and B-trichothecenes in wheat flour. J. Chromatogr. A, 1217, 14371440.

Varela, G., Moreiras, O., Carbajal, A., Campo, M. (1995). Encuesta de presupuestos familiares 1990-1991. Estudio nacional de nutrición y alimentación. Madrid: Instituto Nacional de Estadística.

World Health Organization (WHO) (2001). Safety evaluation of certain mycotoxins in food. Prepared by the Fifty-sixth meeting of the Joint FAO/WHO Expert Committee on Food Additives. 47. 


\section{Figure captions}

Figure 1. Chemical structure of type-A and type-B trichothecenes.

Figure 2. Superposition of a chromatogram obtained from a matrix-matched standard $10 \mathrm{ng} \mathrm{kg}^{-1}(--)$, and from a naturally contaminated barley sample $(-)$.

Figure 3. Concentration levels of trichothecenes in the samples with more than one mycotoxin. 


\section{FIGURES}

Figure 1

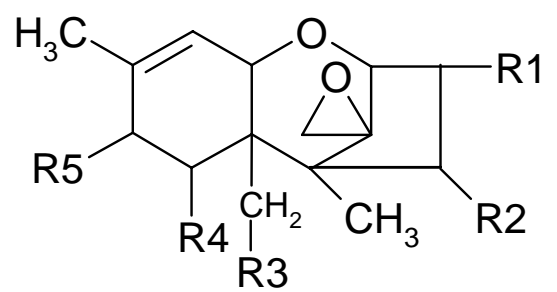

¡Error!

Vínculo

no

válido. 
Figure 2

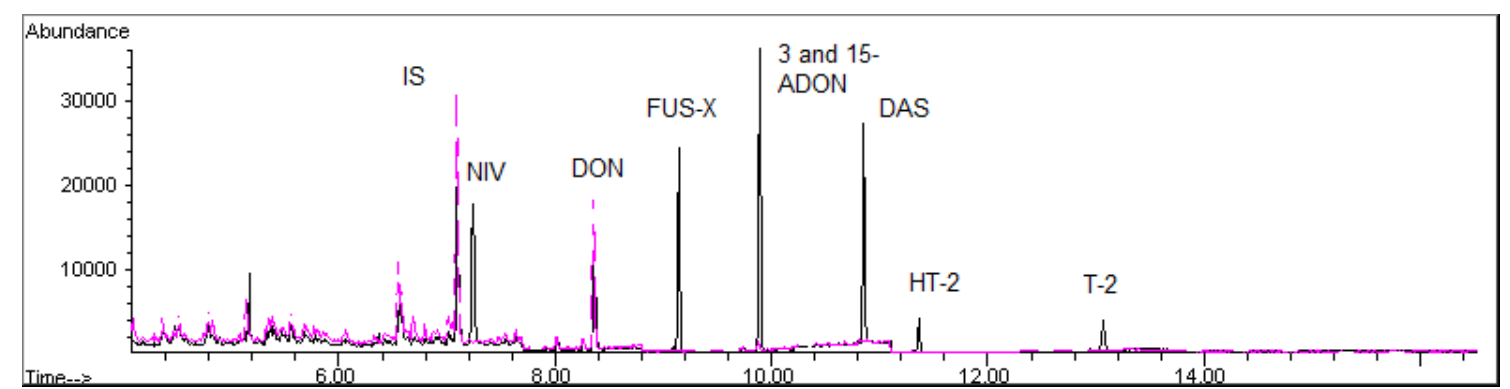


Figure 3

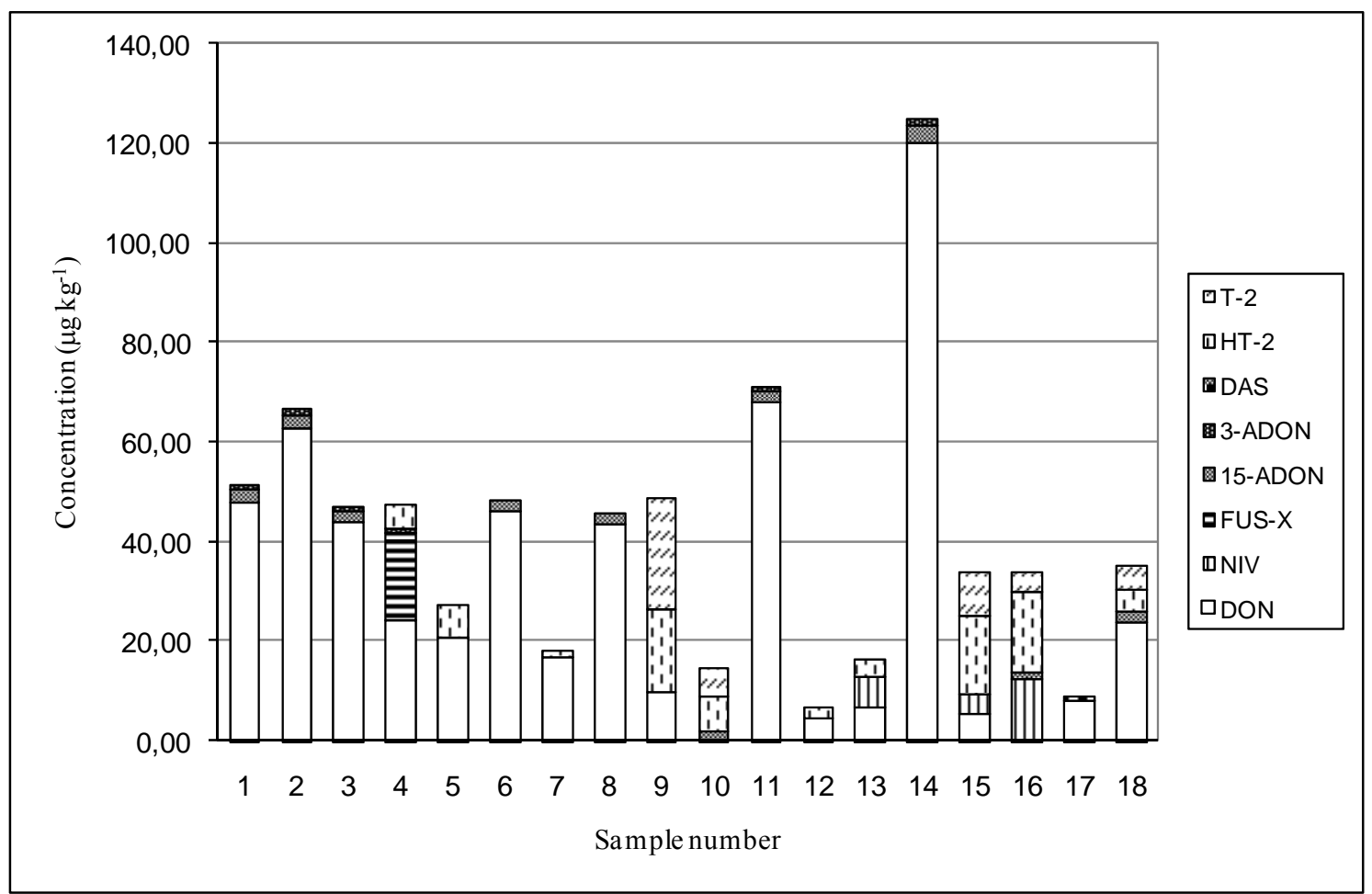




\section{TABLES}

Table 1. Retention time, ions monitored and linearity data.

\begin{tabular}{|c|c|c|c|c|c|c|c|}
\hline Mycotoxin & Analyte & $\begin{array}{l}\text { Retention } \\
\text { time (min) }\end{array}$ & $\operatorname{SIM}(\mathbf{m} / \mathbf{z})$ & Range ( $\mu g \mathrm{~kg}^{-1}$ ) & curve equation & $\mathbf{r}^{2}$ & $\begin{array}{c}\text { Slope } \\
\text { interval }(p=95 \%)\end{array}$ \\
\hline & ${\mathrm{CLO}-\mathrm{PFP}_{2}}_{2}$ & 7.11 & $273,301,629$ & & & & \\
\hline NIV & NIV-PFP 4 & 7.25 & $271,307,459,705,733$ & $\begin{array}{c}10-200 \\
200-2000\end{array}$ & $\begin{array}{c}y=1.02 \cdot 10^{-2} x-5.3 \cdot 10^{-3} \\
y=1.36 \cdot 10^{-2} x-1.02\end{array}$ & 0.997 & $\begin{array}{l}0.0092,0.0112 \\
0.0125,0.0147\end{array}$ \\
\hline DON & $\mathrm{DON}_{-} \mathrm{PFP}_{3}$ & 8.38 & $309,407,570,734$ & $\begin{array}{c}20-200 \\
200-2000\end{array}$ & $\begin{array}{l}y=5.72 \cdot 10^{-3} x+1.6 \cdot 10^{-3} \\
y=7.34 \cdot 10^{-3} x-3.80 \cdot 10^{-1}\end{array}$ & $\begin{array}{l}0.993 \\
0.998\end{array}$ & $\begin{array}{l}0.0050,0.0064 \\
0.0068,0.0078\end{array}$ \\
\hline FUS-X & FUS-X-PFP 3 & 9.15 & $527,569,601,792$ & $\begin{array}{c}10-200 \\
200-2000\end{array}$ & $\begin{array}{l}y=9.68 \cdot 10^{-3} x-5.59 \cdot 10^{-3} \\
y=1.19 \cdot 10^{-2} x-5.57 \cdot 10^{-1}\end{array}$ & $\begin{array}{l}0.996 \\
0.999\end{array}$ & $\begin{array}{l}0.0089,0.0105 \\
0.0114,0.0124\end{array}$ \\
\hline 15-ADON & $15-A D O N-P_{2}$ & 9.90 & $394,570,630$ & $\begin{array}{c}10-200 \\
200-2000\end{array}$ & $\begin{array}{l}y=8.48 \cdot 10^{-3} x-1.34 \cdot 10^{-2} \\
y=1.03 \cdot 10^{-2} x-6.13 \cdot 10^{-1}\end{array}$ & $\begin{array}{l}1.000 \\
0.999\end{array}$ & $\begin{array}{l}0.0083,0.0086 \\
0.0097,0.0108\end{array}$ \\
\hline 3-ADON & 3-ADON-PFP 2 & 9.90 & $588,570,630$ & $\begin{array}{c}10-200 \\
200-2000\end{array}$ & $\begin{array}{c}y=4.6 \cdot 10^{-3} x+6.9 \cdot 10^{-4} \\
y=5.89 \cdot 10^{-3} x-3.99 \cdot 10^{-1}\end{array}$ & $\begin{array}{l}0.999 \\
0.999\end{array}$ & $\begin{array}{l}0.0044,0.0048 \\
0.0056,0.0062\end{array}$ \\
\hline $\mathrm{NEO}$ & NEO-PFP 2 & 10.70 & $424,451,511$ & & & & \\
\hline DAS & DAS-PFP & 10.86 & $379,409,452$ & $\begin{array}{c}10-200 \\
200-2000\end{array}$ & $\begin{array}{l}y=1.08 \cdot 10^{-2} x+2.70 \cdot 10^{-3} \\
y=1.20 \cdot 10^{-2} x-4.47 \cdot 10^{-1}\end{array}$ & $\begin{array}{l}0.998 \\
1.000\end{array}$ & $\begin{array}{l}0.0102,0.0114 \\
0.0117,0.0123\end{array}$ \\
\hline HT-2 & HT-2-PFP 2 & 11.37 & $542,572,716$ & $\begin{array}{c}20-200 \\
200-2000\end{array}$ & $\begin{array}{l}y=1.51 \cdot 10^{-3} x+1.11 \cdot 10^{-3} \\
y=1.81 \cdot 10^{-3} x-8.71 \cdot 10^{-2}\end{array}$ & 1.000 & $0.0018,0.0019$ \\
\hline $\mathrm{T}-2$ & $\mathrm{~T}-2-\mathrm{PFP}$ & 13.08 & 451 & $\begin{array}{c}10-200 \\
200-2000\end{array}$ & $\begin{array}{l}y=2.17 \cdot 10^{-3} x-6.61 \cdot 10^{-3} \\
y=2.50 \cdot 10^{-3} x-1.40 \cdot 10^{-1}\end{array}$ & $\begin{array}{l}0.994 \\
0.997\end{array}$ & $\begin{array}{l}0.0019,0.0024 \\
0.0023,0.0027\end{array}$ \\
\hline
\end{tabular}


Table 2. LOD, LOQ, precision and recovery.

\begin{tabular}{|c|c|c|c|c|c|c|c|}
\hline \multirow[t]{2}{*}{ Mycotoxin } & \multirow{2}{*}{$\underset{\left(\mu \mathrm{kg}^{-1}\right)}{\mathrm{LOD}}$} & \multirow{2}{*}{$\underset{\left(\mu g k^{-1}\right)}{L O Q}$} & \multirow{2}{*}{$\begin{array}{l}\text { Toxin added } \\
\left(\mu \mathrm{kg}^{-1}\right)\end{array}$} & \multicolumn{2}{|c|}{$\begin{array}{l}\text { Within-day recovery } \\
\text { (RSD; \%) }\end{array}$} & \multicolumn{2}{|c|}{$\begin{array}{c}\text { Between-day recovery } \\
\text { (RSD; \%) }\end{array}$} \\
\hline & & & & $(n=3)$ & Global $(n=9)$ & $(\mathbf{n}=9)$ & Global $(n=27)$ \\
\hline \multirow{3}{*}{ NIV } & \multirow{3}{*}{1.3} & \multirow{3}{*}{10.00} & 20 & $72.4(8.6)$ & \multirow{3}{*}{$66.3(12.9)$} & $68.4(8.7)$ & \multirow{3}{*}{$63.1(10.7)$} \\
\hline & & & 100 & $69.6(7.7)$ & & $63.4(9.6)$ & \\
\hline & & & 1000 & $56.7(6.3)$ & & $57.3(4.6)$ & \\
\hline \multirow{3}{*}{ DON } & \multirow{3}{*}{3.9} & \multirow{3}{*}{20.0} & 20 & $99.9(7.9)$ & \multirow{3}{*}{94.7 (11.6) } & $105.8(11.3)$ & \multirow{3}{*}{$99.8(11.2)$} \\
\hline & & & 100 & $102.5(4.2)$ & & $105.1(3.7)$ & \\
\hline & & & 1000 & $81.7(4.3)$ & & $88.3(6.1)$ & \\
\hline \multirow{3}{*}{ FUS-X } & \multirow{3}{*}{1.1} & \multirow{3}{*}{10.0} & 20 & $94.4(1.8)$ & \multirow{3}{*}{$91.6(6.7)$} & $99.9(4.8)$ & \multirow{3}{*}{$96.1(6.2)$} \\
\hline & & & 100 & $96.4(2.7)$ & & $98.2(2.6)$ & \\
\hline & & & 1000 & $84.0(3.0)$ & & $90.3(5.6)$ & \\
\hline \multirow{3}{*}{ 15-ADON } & \multirow{3}{*}{0.3} & \multirow{3}{*}{10.0} & 20 & $97.1(4.4)$ & \multirow{3}{*}{$94.7(4.4)$} & $97.9(6.2)$ & \multirow{3}{*}{$94.5(5.4)$} \\
\hline & & & 100 & $96.2(0.7)$ & & $93.5(4.7)$ & \\
\hline & & & 1000 & $90.6(3.9)$ & & $92.2(3.3)$ & \\
\hline \multirow{3}{*}{ 3-ADON } & \multirow{3}{*}{0.7} & \multirow{3}{*}{10.0} & 20 & $86.1(1.8)$ & \multirow{3}{*}{$88.4(6.0)$} & $90.3(9.2)$ & \multirow{3}{*}{$92.0(7.2)$} \\
\hline & & & 100 & $94.6(1.0)$ & & $95.7(5.0)$ & \\
\hline & & & 1000 & $84.4(5.4)$ & & $89.9(5.7)$ & \\
\hline \multirow{3}{*}{ DAS } & & & 20 & $95.3(1.2)$ & & $97.4(8.4)$ & \\
\hline & 0.5 & 10.0 & 100 & $104.3(0.9)$ & $101.5(5.1)$ & $102.3(7.7)$ & $101.9(7.4)$ \\
\hline & & & 1000 & $104.8(4.1)$ & & $105.9(3.4)$ & \\
\hline & & & 20 & $88.0(4.1)$ & & $96.9(8.2)$ & \\
\hline HT-2 & 2.0 & 20.0 & 100 & $100.8(1.1)$ & $95.0(6.5)$ & $99.8(2.2)$ & $97.8(5.3)$ \\
\hline & & & 1000 & $96.2(3.4)$ & & $96.7(3.4)$ & \\
\hline & & & 20 & $96.2(10.0)$ & & $100.9(10.0)$ & \\
\hline $\mathrm{T}-2$ & 0.4 & 20.0 & 100 & $101.6(2.1)$ & $99.8(6.0)$ & $98.0(7.1)$ & $99.5(7.3)$ \\
\hline & & & 1000 & $101.5(4.3)$ & & $99.5(4.1)$ & \\
\hline
\end{tabular}


Table 3. Trichothecene levels $\left(\mu \mathrm{g} \mathrm{kg}^{-1}\right)$ in barley samples.

\begin{tabular}{ccccccccc}
\hline Parameters & NIV & DON & FUS-X & 15-ADON & 3-ADON & DAS & HT-2 & T-2 \\
\hline Positive samples (\%) & 7 & 89 & 2 & 20 & 14 & 5 & 23 & 11 \\
Mean value of positive samples & 7.40 & 21.75 & 17.45 & 2.43 & 1.04 & 0.88 & 7.82 & 9.15 \\
$\left(\mu \mathrm{kg}^{-1}\right)$ & & & & & & & \\
Mean value $\left(\mu \mathrm{g} \mathrm{kg}^{-1}\right)$ & 1.13 & 19.49 & 0.95 & 0.62 & 0.44 & 0.30 & 2.21 & 1.20 \\
Median value $\left(\mu \mathrm{gg}^{-1}\right)$ & 0.67 & 11.48 & 0.57 & 0.15 & 0.35 & 0.27 & 0.56 & 0.18 \\
Maximum level found $\left(\mu \mathrm{g} \mathrm{kg}^{-1}\right)$ & 12.47 & 119.89 & 17.45 & $3.49^{*}$ & $1.68^{*}$ & $1.11^{*}$ & $16.38^{*}$ & 22.56 \\
\hline$*:<\mathrm{LOQ}$ & & & & & & & &
\end{tabular}


Table 4. Calculated dietary intake of Fusarium toxins.

\begin{tabular}{|c|c|c|c|c|c|c|}
\hline \multirow{2}{*}{ Mycotoxin } & \multicolumn{2}{|c|}{ Level $\left(\mu g \mathrm{~kg}^{-1}\right)$} & \multicolumn{2}{|c|}{ Daily intake ( $\mu \mathrm{g} \mathrm{kg}^{-1}$ w.b.) ${ }^{*}$} & \multicolumn{2}{|c|}{ \%TDI } \\
\hline & Mean & Maximum & Mean & Maximum & Mean & Maximum \\
\hline DON & 19.5 & 119.9 & 0.1 & 0.4 & 6.7 & 40.9 \\
\hline NIV & 1.1 & 12.5 & $4 \cdot 10^{-3}$ & $43 \cdot 10^{-3}$ & 0.5 & 6.1 \\
\hline $\mathrm{T}-2+\mathrm{HT}-2$ & 3.4 & 38.8 & $12 \cdot 10^{-3}$ & 0.1 & 16.6 & 189.4 \\
\hline
\end{tabular}

